\title{
Comentario de Jurisprudencia reciente del Tribunal de Justicia de la Unión Europea
}

\author{
David Ordóñez Solís \\ Magistrado, doctor en Derecho \\ y miembro de la Red de Expertos en Derecho de la Unión Europea
}

\begin{abstract}
Sumario: I. Introducción.-II. Primera parte. Derechos fundamentales, ciudadanía de la unión e internet. 1. Las discriminaciones por razón de la edad (sentencia Prigge) y por la orientación sexual (sentencia Römer). 2. Los efectos de la ciudadanía de la Unión para los nacionales de terceros Estados (sentencias Ruiz Zambrano y Dereci). 3. Los derechos fundamentales en Internet (sentencias L'Oréal y Scarlet Extended).--III. Segunda parte. Mercado Único Europeo: libre competencia y libertades económicas (decodificadores y notarios). 1. La aplicación de la libre competencia por las autoridades nacionales y los límites del Derecho de la Unión (sentencias Pfleiderer y Tele2 Polska). 2. La libre circulación de servicios y los decodificadores de televisión (sentencia Football Association Premier League). 3. El acceso a la profesión de notario y la prohibición de discriminación por razón de la nacionalidad. - IV. Tercera parte. La jurisprudencia del Tribunal de Justicia y el derecho español. 1. Los reenvíos prejudiciales de los jueces españoles: la primera cuestión prejudicial del Tribunal Constitucional (asunto Melloni). 2. Las sentencias dictadas por el Tribunal de Justicia en respuesta a reenvíos prejudiciales de los tribunales españoles. 3. Las sentencias declarativas del incumplimiento del Reino de España (licencias, anuncios televisivos y urbanismo valenciano). V. Relación de las sentencias comentadas del Tribunal de Justicia.
\end{abstract}

\section{Introducción}

El Derecho de la Unión Europea ha llegado a ser lo que es debido a la interpretación del Tribunal de Justicia, hasta el punto de que la jurisprudencia comunitaria europea constituye, junto con la del Tribunal Europeo de Derechos Humanos de Estrasburgo, una de las contribuciones jurídicas más importantes de nuestra sociedad.

Esta crónica de la jurisprudencia comprende 2011 por lo que ha de situarse en su propio contexto, es decir, en el segundo año de aplicación de las reformas introducidas por el Tratado de Lisboa, en vigor desde el 1 de diciembre de 2009, y durante este periodo se ha podido observar una con- 
solidación de líneas jurisprudenciales tradicionales y la apertura de nuevas perspectivas.

Como sería imposible dar cuenta de toda la jurisprudencia desarrollada o incluso de las más importantes sentencias, en los términos ya tradicionales de los Informes anuales de actividad del propio Tribunal de Justicia de la Unión Europea, me propongo el examen de 24 sentencias y un auto enumerados al final de la Crónica y que giran en torno a tres líneas argumentativas: los derechos fundamentales, el mercado único y el Derecho español.

La primera línea está vinculada a los derechos fundamentales, la ciudadanía de la Unión e Internet. La segunda línea de examen se refiere a la realización del mercado único europeo tanto en lo que se refiere a la aplicación del derecho de la competencia como a la realización de las libertades económicas fundamentales respecto de los decodificadores de televisión y de los notarios; Y, por último, presento los aspectos más sobresalientes de la cooperación entre los tribunales españoles y el Tribunal de Justicia, destacando de modo especial el primer reenvío prejudicial del Tribunal Constitucional español y las sentencias del Tribunal de Justicia pronunciadas en respuesta a reenvíos prejudiciales y declarativas de incumplimientos «españoles».

\section{Primera parte. Derechos fundamentales, ciudadanía de la Unión e internet}

La integración europea se ha caracterizado por la creación de una Comunidad de Derecho y ahora de una Unión de Derecho en la que son esenciales las libertades económicas fundamentales, que constituyen la razón de ser de mercado, y los derechos fundamentales. Mientras aquellas fueron objeto de especial protección desde el principio de las Comunidades Europeas, la protección de los derechos fundamentales se ha desarrollado jurisprudencialmente por el Tribunal de Justicia como consecuencia del aliento de algunos Tribunales Constitucionales en los años 70 y 80; y desde la adopción de la Carta de Derechos Fundamentales en Niza en 2000 y, más recientemente, con la consagración de la Carta de Derechos Fundamentales de la Unión adoptada en Estrasburgo en 2007 y que desde el 1 de diciembre de 2009 tiene el mismo valor jurídico que los Tratados constitutivos. Probablemente el punto de unión entre las libertades económicas fundamentales y los derechos humanos en la Unión sea la consagración de una ciudadanía europea que ha permitido los más importantes desarrollos jurisprudenciales desde el Tratado de Maastricht de 1992. 


\section{Las discriminaciones por razón de la edad (sentencia Prigge) y por la orientación sexual (sentencia Römer)}

Los progresos más espectaculares que se han producido en Europa precisamente de la mano del Tribunal de Justicia lo han sido en materia de discriminación. De hecho, en 2011 el Tribunal de Justicia interpreta la Directiva 2000/78/CE relativa al establecimiento de un marco general para la igualdad de trato en el empleo y la ocupación en dos sentencias relevantes que constatan la discriminación contraria al Derecho de la Unión por razón de la edad (sentencia Prigge) y por la orientación sexual (sentencia Römer).

La sentencia Prigge es el resultado de un reenvío prejudicial del Tribunal Supremo de lo Social de Alemania en un asunto que enfrentaba a varios pilotos con la compañía aérea Lufthansa. La cuestión planteada es si se puede prohibir, como hace el convenio colectivo aplicable en Alemania, la contratación de pilotos comerciales a partir del momento en que cumplen los 60 años.

El punto de partida del Tribunal de Justicia es que la Directiva 2000/78/ CE concreta el principio de no discriminación por razón de la edad en el ámbito del empleo y la ocupación; pero también recuerda que el mismo principio se proclama en el artículo 21 de la Carta de los Derechos Fundamentales de la Unión Europea, precisando que la Carta, desde el 1 de diciembre de 2009, tiene el mismo valor jurídico que los Tratados constitutivos (apartado 38).

A partir de este principio, el Tribunal de Justicia comprueba que «las normativas nacional e internacional consideraron necesario, no ya prohibir a los pilotos ejercer sus actividades después de los 60 años, sino únicamente restringir dicho ejercicio. Por lo tanto, la prohibición de pilotar después de dicha edad, contenida en [un convenio colectivo] no era necesaria para la consecución del objetivo perseguido».

Por tanto, el Tribunal de Justicia deduce, por una parte, que «la Directiva 2000/78/CE debe interpretarse en el sentido de que se opone a que una cláusula de un convenio colectivo [...] fije en 60 años el límite de edad a partir del cual se considera que los pilotos no poseen ya las capacidades físicas necesarias para ejercer su actividad, pese a que las normativas nacional e internacional fijan esta edad en 65 años»; y, por otra parte, comprueba que la seguridad aérea no es un objetivo legítimo que pueda justificar las excepciones al principio de no discriminación. En este sentido el Tribunal de Justicia recuerda que pueden establecerse excepciones al principio de no discriminación por razón de la edad si persiguen «objetivos de política social, como los vinculados a las políticas de empleo, del mercado de trabajo o de la formación profesional» (apartados 81 y 82). 
La no discriminación por orientación sexual se reafirma en la sentencia Römer que tiene su origen en una cuestión prejudicial planteada por el Tribunal social de Hamburgo. La respuesta del Tribunal de Justicia tiene importancia no solo porque resuelve el litigio relativo a la discriminación de las parejas del mismo sexo sino también porque confirma los principios básicos de aplicación del Derecho de la Unión Europea, especialmente la primacía y el efecto directo.

El Sr. Römer, empleado de la ciudad de Hamburgo, convivía desde 1969 con otro hombre y había inscrito su relación como pareja de hecho; sin embargo, al calcular la pensión complementaria de jubilación, no se le aplicó una deducción para los casos de matrimonio lo que suponía una merma de unos 300 euros mensuales.

La primera cuestión que aclara el Tribunal de Justicia es que resulta aplicable a este tipo de pensiones de jubilación la Directiva 2000/78/CE relativa al establecimiento de un marco general para la igualdad de trato en el empleo y la ocupación (apartado 36).

La segunda cuestión obliga al Tribunal de Justicia a determinar, después de considerar que la situación y la regulación del matrimonio y de las parejas de hecho son análogas, si se produce una discriminación por razón de la orientación sexual. A tal efecto, considera que «el estado civil del interesado no influyó en absoluto en las cotizaciones que, en relación con la prestación sobre la que versa el litigio principal, hubo de abonar durante su vida laboral, ya que se vio obligado a contribuir a los gastos de las pensiones pagando una cotización igual a la de sus compañeros de trabajo casados» (apartado 51). Y comprueba que la pensión del Sr. Römer habría aumentado de haber contraído matrimonio, en lugar de constituir una pareja estable inscrita con un hombre. Por lo que el Tribunal concluye que «existe una discriminación por motivos de orientación sexual, debido al hecho de que, en el Derecho nacional, la mencionada pareja estable inscrita se encuentra en una situación jurídica y fáctica análoga a la de una persona casada a los efectos de la pensión de que se trata» (apartado 52).

Asimismo, y frente a cualquier reticencia sobre la aplicación de esta Directiva, el Tribunal de Justicia insiste: «Según reiterada jurisprudencia, el juez nacional encargado de aplicar, en el marco de su competencia, las disposiciones del Derecho de la Unión, está obligado a garantizar la plena eficacia de estas normas dejando inaplicada en caso de necesidad, por su propia iniciativa, cualquier disposición contraria de la legislación nacional, incluso posterior, sin solicitar o esperar su previa derogación por el legislador o mediante cualquier otro procedimiento constitucional» (apartado 54).

Por último, el Tribunal de Justicia establece como fecha de aplicación de este derecho la que coincide con el fin del plazo de transposición de la Directiva 2000/78/CE: «el derecho a la igualdad de trato no podrá ser invo- 
cado por un particular como el demandante en el litigio principal antes de haber finalizado el plazo de transposición de dicha Directiva, a saber, a partir del 3 de diciembre de 2003, pero sin que para ello resulte necesario esperar a que el legislador nacional haya adoptado las medidas necesarias para adecuar la citada disposición al Derecho de la Unión».

2. Los efectos de la ciudadanía de la Unión para los nacionales de terceros Estados (sentencias Ruiz Zambrano y Dereci)

La consagración por el Tratado de Maastricht en 1992 del nuevo concepto de ciudadanía de la Unión ha permitido que el Tribunal de Justicia lo desarrolle pero no sin antes sujetarlo a numerosas cautelas que en ocasiones hacen difícil interpretar la jurisprudencia de Luxemburgo. Así sucede en los desarrollos de 2011 y en dos sentencias complementarias como la dictada en el asunto Ruiz Zambrano y la dictada en el asunto Dereci.

En la sentencia Ruiz Zambrano el Tribunal de Justicia se pronuncia sobre el alcance de la ciudadanía de la Unión y, como ya había señalado en otras ocasiones, considera que la ciudadanía de la Unión de los menores de edad aprovecha a los padres con la nacionalidad de terceros países. Ahora bien y en este supuesto se plantea la espinosa cuestión de si estamos ante una situación puramente interna o no que impida a la ciudadanía de la Unión desplegar todos sus efectos.

Gerardo Ruiz Zambrano es de nacionalidad colombiana y reside desde 1999 en Bélgica con su esposa también colombiana; a pesar de no tener permiso de trabajo fue contratado desde 2001 por una empresa en Bélgica; asimismo, su segundo y su tercer hijo adquirieron al nacer la nacionalidad belga. Después de sucesivas denegaciones de autorización de residencia y de trabajo, reclama su derecho de residencia y un permiso de trabajo ante el tribunal de trabajo de Bruselas por ser el padre de dos hijos belgas.

Por una parte, el Tribunal de Justicia puntualiza que la ciudadanía de la Unión depende de la nacionalidad de cada Estado miembro por lo que no hay duda de que sus dos últimos hijos tienen la nacionalidad belga y, en consecuencia, son ciudadanos de la Unión.

Seguidamente, el Tribunal de Justicia enuncia el principio conforme al cual: «la vocación del estatuto de ciudadano de la Unión es convertirse en el estatuto fundamental de los nacionales de los Estados miembros» (apartado 41) y del mismo deduce esta consecuencia: «el artículo 20 TFUE se opone a medidas nacionales que tengan por efecto privar a los ciudadanos de la Unión del disfrute efectivo de la esencia de los derechos conferidos por su estatuto de ciudadano de la Unión» (apartado 42). Lo que aplicado al caso concreto supone que «la negativa a conceder un permiso de residen- 
cia a una persona, nacional de un Estado tercero, en el Estado miembro en el que residen sus hijos de corta edad, nacionales de dicho Estado miembro, cuya manutención asume, y la negativa a concederle un permiso de trabajo, tienen tal efecto» (apartado 43).

Debe subrayarse que, en realidad, la situación planteada en la sentencia Ruiz Zambrano es puramente interna dado que los dos hijos belgas nunca ejercieron el derecho de circulación en la Unión; sin embargo, el Tribunal de Justicia crea una regla específica de protección de los ciudadanos de la Unión para el caso de que los ciudadanos de la Unión se vean, de hecho, en la imposibilidad de ejercer la esencia de los derechos que les confiere su estatuto de ciudadanía. Es decir, si las autoridades belgas deniegan la autorización de residencia y el permiso de trabajo al Sr. Ruiz Zambrano sus dos hijos menores, a pesar de ser ciudadanos europeos, deberían abandonar el territorio de la Unión con su progenitor, nacional colombiano.

Parece que la solución más detallada se recoge en la sentencia Dereci en la que el Tribunal de Justicia sigue el procedimiento acelerado dado que se le han planteado numerosos asuntos similares y era previsible, a su juicio, un aumento de este tipo de asuntos como consecuencia de la sentencia Ruiz Zambrano.

El litigio principal se había planteado ante el Tribunal Supremo administrativo austriaco entre cinco nacionales de Turquía, Nigeria, Sri Lanka, Yugoslavia y Serbia que residían desde hacía tiempo en Austria y estaban casados o sus padres adquirieron la nacionalidad austríaca, y a los que, sin embargo, se les había denegado el permiso de residencia.

La primera cuestión que aborda el Tribunal de Justicia se refiere a la interpretación de la sentencia Ruiz Zambrano. A tal efecto, puntualiza que la denegación del permiso de residencia y de trabajo al padre de dos niños menores que son ciudadanos de la Unión les supondría que estarían obligados a abandonar la Unión para acompañar a su padres por lo que en tales condiciones los ciudadanos de la Unión se verían, de hecho, en la imposibilidad de ejercer lo sustancial de los derechos conferidos por su estatuto como ciudadanos de la Unión (apartado 65). Por tanto, subrayar el Tribunal de Justicia que se trata de un «criterio relativo a la privación del contenido sustancial de los derechos conferidos por el estatuto de ciudadano de la Unión» (apartado 66) y constituye una interpretación excepcional para evitar que la ciudadanía de la Unión no produzca sus efectos (apartado 67).

De hecho y en el caso concreto, parece deducirse de su respuesta que el Tribunal de Justicia considera que la denegación del permiso de residencia no sería contraria a la ciudadanía de la Unión de miembros de su familia que nunca han hecho uso de su derecho a la libre circulación en la medida en que tal denegación no comporte, para el ciudadano de la Unión con 
quien convive, la privación del disfrute efectivo del contenido esencial de los derechos que le confiere el estatuto de ciudadano de la Unión.

En segundo lugar, el Tribunal de Justicia ensaya una interpretación para los supuestos en que se aplique el Derecho de la Unión y, más en particular, cuando resulta aplicable la Carta de los Derechos Fundamentales de la Unión, y para los demás casos en que se aplicaría el Convenio Europeo de Derechos Humanos. De modo que si el tribunal nacional considera aplicable el Derecho de la Unión deberá examinar si la denegación del derecho de residencia respeta el derecho a la vida privada y familiar del artículo 7 de la Carta; si no se aplica el Derecho de la Unión, el examen deberá hacerse a la luz del artículo 8 del Convenio Europeo.

Por último, el Tribunal de Justicia, en relación con el nacional turco, el Sr. Dereci (casado con una austriaca y padre de tres niños austriacos), le reconoce el derecho de invocar ante los jueces austriacos la inaplicabilidad de una legislación nacional posterior que es más gravosa que la anterior por la que se le reconocía como miembro de una familia austriaca la libertad de establecimiento (apartados 87 y 97).

\section{Los derechos fundamentales en Internet (sentencias L'Oréal y Scarlet Extended)}

La generalización de Internet ha supuesto que en los más variados ámbitos, especialmente del comercio y del ejercicio de los derechos fundamentales, surjan cuestiones que ha tenido que resolver el Tribunal de Justicia. En esta línea se inscriben precisamente la sentencia L'Oréal relativa al uso de una marca en Internet y la sentencia Scarlet Extended sobre los límites a la potestad judicial en lo que se refiere a las descargas ilegales.

La sentencia L'Oréal tiene su origen en el uso fraudulento de una marca en el mercado electrónico, y se refiere expresamente al problema de la identificación del operador, «cuando el autor de la infracción actúa en el tráfico comercial y no en el ámbito de la esfera de su vida privada», que haya vulnerado un derecho de propiedad intelectual. En este asunto se enfrentaba L'Oréal - la conocida empresa de cosméticos y titular de marcas muy renombradas de perfumes - con eBay - la no menos famosa empresa de subastas en Internet-. L'Oréal presentó una demanda ante la High Court of Justice en Londres contra eBay y varias personas físicas que a través de la plataforma de Internet habían vendido 17 productos falsificados o sin cumplir las condiciones de embalaje de la marca.

Aun cuando las cuestiones relativas a la marca son especialmente relevantes en esta sentencia, baste recordar solo tres de sus aspectos esenciales. 
Por una parte y a juicio del Tribunal de Justicia: «el titular de la marca puede, no obstante, oponerse a que se revenda sin embalaje un perfume o un producto cosmético designado con la marca de la que es titular si demuestra que la retirada del embalaje menoscaba la imagen de dicho producto y, en consecuencia, la reputación de la marca» (apartado 83).

Por otra parte, el Tribunal de Justicia puntualiza: «el titular de una marca está facultado para prohibir al operador de un mercado electrónico hacer publicidad, a partir de una palabra clave idéntica a esa marca y que ha sido seleccionada por ese operador en el contexto de un servicio de referenciación en Internet, de productos de tal marca que se ponen a la venta en ese mercado electrónico cuando dicha publicidad no permite o apenas permite al internauta normalmente informado y razonablemente atento determinar si tales productos proceden del titular de la marca o de una empresa económicamente vinculada a éste o si, por el contrario, proceden de un tercero» (apartado 97).

En fin, el Tribunal de Justicia precisa el alcance de la responsabilidad del operador del mercado electrónico, en este caso e-Bay, y señala que, aun cuando el operador del mercado electrónico no haya desempeñado un papel activo, «ese operador no podrá, no obstante, en un asunto que puede concluir con una condena al pago de una indemnización por daños y perjuicios, acogerse a la exención de responsabilidad prevista [...] cuando haya tenido conocimiento de hechos o circunstancias a partir de los cuales un operador económico diligente hubiera debido constatar el carácter ilícito de las ofertas de venta en cuestión y, en caso de adquirir tal conocimiento» (apartado 124).

Ahora bien, me gustaría subrayar el alcance de los requerimientos judiciales dirigidos al operador del mercado electrónico, es decir, lo que el juez nacional puede hacer a instancia de un titular de una marca que considere vulnerados sus derechos, en este caso L'Oréal respecto de e-Bay y los que utilizaron fraudulentamente la marca. Pues bien y basándose en la Directiva 2004/48/CE, el Tribunal de Justicia considera que para proteger efectivamente la propiedad intelectual, los jueces nacionales «puedan requerir al prestador de un servicio en línea, como el consistente en poner a disposición de los internautas un mercado electrónico, que adopte medidas que contribuyan eficazmente no solo a poner término a las lesiones causadas a través de ese mercado electrónico, sino también a evitar nuevas lesiones» (apartado 131).

El Tribunal de Justicia se refiere, asimismo, a que tales requerimientos judiciales sean efectivos y proporcionados de modo que «si el operador del mercado electrónico no decide motu proprio suspender la cuenta de quien vulneró los derechos de propiedad intelectual para evitar que el mismo comerciante vuelva a cometer infracciones de esta naturaleza en relación con las mismas marcas, podrá ser obligado a ello mediante un requerimiento judicial» (apartado 141). 
Por último, el Tribunal de Justicia se pronuncia sobre los límites de estos requerimientos y, en particular, sobre la protección de datos; sin embargo, puntualiza: «si bien es cierto que resulta necesario respetar la protección de datos personales, no lo es menos que, cuando el autor de la infracción actúa en el tráfico comercial y no en el ámbito de la esfera de su vida privada, éste debe ser claramente identificable» (apartado 142).

La sentencia Scarlet Extended aborda la cuestión de la lucha contra las descargas ilegales y de los límites que imponen los derechos fundamentales a la protección judicial de los derechos de autor.

Se trata de un reenvío prejudicial procedente de un tribunal de apelación belga que, en realidad, pretende desentrañar el problema jurídico planteado en la sentencia de 29 de enero de 2008, Promusicae (C-275/06) pero en este caso en relación con la aplicación de un sistema de filtrado y bloqueo de la transmisión de datos electrónicos autorizado por el Derecho belga. A tal efecto, SABAM, la sociedad de autores de Bélgica había solicitado al juez nacional la adopción de una medida cautelar de cesación frente a Scarlet, una empresa prestadora de servicios de acceso a Internet (PAI), con el fin de evitar el pirateo realizado por determinados internautas. El tribunal belga de primera instancia accedió a la solicitud de SABAM, ordenó el cese de los atentados a los derechos de autor y, de conformidad con un informe técnico, exigió la aplicación de un procedimiento informático que impidiese el intercambio de ficheros que contuviesen una obra musical del repertorio de la sociedad de autores. Sin embargo, Scarlet formuló recurso ante el Tribunal de apelaciones de Bruselas que acudió en vía prejudicial a Luxemburgo.

El Derecho nacional invocado es precisamente una Ley belga que transpone las Directivas 2001/29/CE y 2004/48/CE y que, en particular, permite al juez nacional constatar la existencia y ordenar la cesación de cualquier atentado a un derecho de autor o a otro derecho similar para lo que puede adoptar una orden de cesación frente a los intermediarios cuyos servicios sean utilizados por un tercero para atentar contra tales derechos.

En sus Conclusiones de 14 de abril de 2011, el abogado general Pedro Cruz Villalón hace una interpretación muy interesante de los límites o de las restricciones que pueden imponerse al derecho fundamental de protección de datos personales. A tal efecto, adopta las mismas técnicas de interpretación del Convenio Europeo utilizadas por el Tribunal Europeo de Derechos Humanos en relación con la Carta de los Derechos Fundamentales de la Unión Europea de 2007 y propone reformular la cuestión que hace el tribunal belga respecto del Convenio de 1950 por la interpretación de las disposiciones de la Carta (apartado 34 de las Conclusiones).

Y a partir de ahí el abogado general examina el problema del sistema de filtro y de bloqueo de los servidores de internet. A juicio del abogado general y a pesar de las incertidumbres de naturaleza tecnológica, este sistema de fil- 
tro y de bloqueo es susceptible de afectar de manera incontestable al derecho a la protección de datos personales en un grado suficiente que permite calificarlo de limitación en el sentido del artículo 52.1 de la Carta (apartado 80). A tal efecto, el abogado general determina, con ayuda de la interpretación del Convenio Europeo, cuáles son las condiciones que deben cumplir las limitaciones al ejercicio de los derechos fundamentales de los usuarios: la previsión legal, más en particular, la cobertura por una norma de rango legal, por una norma adoptada por el Parlamento (apartados 100 y 113).

Estos razonamientos llevan al abogado general a proponer que conteste al Tribunal de apelación de Bruselas que el Derecho de la Unión, incluida la Directiva 95/46/CE sobre protección de datos, se opone a que un juez pueda dictar una orden de cesación y de filtro tan radical.

El Tribunal de Justicia sigue esta sugerencia y en su sentencia Scarlet Extended realiza un examen conjunto de las Directivas 2000/31/CE, 2001/29/CE, 2004/48/CE, 95/46/CE y 2002/58/CE, leídas conjuntamente e interpretadas a la luz de los requisitos derivados de la protección de los derechos fundamentales aplicables. La sentencia considera que una «supervisión preventiva [que] exigiría una vigilancia activa de la totalidad de las comunicaciones electrónicas efectuadas en la red del [proveedor de acceso a Internet] afectado y, por lo tanto, comprendería todos los datos que se vayan a transmitir y todos los clientes que utilicen dicha red».

El Tribunal de Justicia recuerda su sentencia Promusicae de la que deduce: «en el marco de las medidas adoptadas para proteger a los titulares de derechos de autor, corresponde a las autoridades y órganos jurisdiccionales nacionales garantizar un justo equilibrio entre la protección de ese derecho y la protección de los derechos fundamentales de las personas afectadas por tales medidas».

Y seguidamente el Tribunal de Justicia llega en la sentencia Scarlet Extended a esta conclusión: «si adoptara el requerimiento judicial por el que se obliga al [proveedor de acceso a Internet] a establecer el sistema de filtrado litigioso, el órgano jurisdiccional nacional en cuestión no respetaría el requisito de garantizar un justo equilibrio entre, por un lado, el derecho de propiedad intelectual y, por otro, la libertad de empresa, el derecho a la protección de datos de carácter personal y la libertad de recibir o comunicar informaciones» (apartado 53).

\section{Segunda parte. Mercado Único Europeo: libre competencia y libertades económicas (decodificadores y notarios)}

En relación con el mercado único europeo el Tribunal de Justicia ha aclarado algunos conceptos básicos sobre la ejecución por las autoridades 
nacionales del Derecho de la competencia, ha desenmarañados los intereses en juego en la radiodifusión de espectáculos deportivos y ha dejado claro que la profesión de notario, al menos en su configuración en varios países, está sometida al Derecho de la Unión y, por tanto, no cabe discriminar en el acceso a tal profesión a los ciudadanos europeos.

\section{La aplicación de la libre competencia por las autoridades nacionales y los límites del Derecho de la Unión (sentencias Pfleiderer y Tele2 Polska)}

La descentralización en la aplicación del Derecho comunitario de la competencia se llevó a cabo a partir del Reglamento (CE) n. ${ }^{\circ}$ 1/2003 relativo a la aplicación de las normas sobre competencia previstas en los artículos 81 y 82 del Tratado y ha requerido un proceso pedagógico de adaptación y de delimitación de competencias de la Comisión y de las autoridades nacionales. Pues bien, en la sentencia Pfleiderer el Tribunal de Justicia recuerda la importancia de la coherencia entre la aplicación de las normas de la competencia; y en la sentencia Tele 2 Polska el Tribunal de Justicia subraya que solo la Comisión Europea puede adoptar una decisión negativa sobre el abuso de posición dominante. En ambos casos la solución se inspira en la aplicación del principio de cooperación entre la Comisión y las autoridades nacionales de competencia.

La sentencia Pfleiderer tiene su origen en una petición de decisión prejudicial planteada por el Tribunal administrativo de Bonn y plantea la relación entre la aplicación pública y la aplicación privada del Derecho de la competencia, y en este caso la protección de los datos personales de quienes se hayan acogido a un programa de clemencia.

El litigio enfrentaba a la empresa Pfleiderer con la autoridad alemana de la competencia (Bundeskartellamt) y se centraba en el derecho de acceso al expediente sancionador seguido contra otras tres empresas competidoras que habían sido sancionadas por vulnerar el Derecho de la competencia. En su origen el Bundeskartellamt, de conformidad con lo establecido en el Tratado CE, impuso multas por importe total de sesenta y dos millones de euros a tres fabricantes europeos de papel decorativo y a cinco personas físicas personalmente responsables, por la celebración de acuerdos sobre precios y de limitación de capacidades de producción. Dado que Pfleiderer había celebrado contratos con algunas de las empresas sancionadas tenía interés en preparar el ejercicio de acciones civiles por daños y perjuicios, por lo que reclamó a la autoridad alemana de la competencia el acceso al expediente sancionador. Sin embargo, el Bundeskartellamt solo facilitó parte de la documentación omitiendo secretos comer- 
ciales y otros datos, por lo que Pfleiderer acudió al Tribunal de Bonn que recurrió al Tribunal de Justicia.

El Tribunal de Justicia pone de manifiesto la importancia de los programas de clemencia y de la aplicación privada del Derecho de la competencia. En efecto, el Tribunal subraya: «los programas nacionales de clemencia son instrumentos útiles en la lucha eficaz para descubrir y detener las vulneraciones de las normas de competencia y sirven, por lo tanto, al objetivo de aplicación efectiva de los artículos 101 TFUE y 102 TFUE» (apartado 25). Pero, a continuación, el Tribunal insiste en lo decisiva que es la aplicación privada del Derecho de la competencia en la medida en que «las acciones que reclaman indemnizaciones por daños y perjuicios ante los órganos jurisdiccionales nacionales pueden contribuir sustancialmente al mantenimiento de una competencia efectiva en la Unión Europea» (apartado 29).

De modo que el Tribunal de Justicia, al haber establecido estos dos puntos de referencia y la utilidad de los mismos (programas de clemencia y private enforcement) encomienda a los jueces nacionales la ponderación caso por caso, en el ámbito del Derecho nacional, y tomando en consideración todos los datos pertinentes del asunto del modo siguiente: «al examinar una solicitud de acceso a los documentos de un programa de clemencia, formulada por una persona que pretende obtener una indemnización por daños y perjuicios de otra persona que es beneficiaria de dicho programa, es necesario velar por que la regulación nacional aplicable no sea menos favorable que la referente a recursos semejantes de naturaleza interna, ni haga imposible en la práctica o excesivamente difícil obtener dicha reparación [...] así como ponderar los intereses que justifican el traslado de la información y la protección de ésta, proporcionada voluntariamente por el solicitante de clemencia» (apartado 30).

La sentencia Tele2 Polska la dicta el Tribunal de Justicia a requerimiento prejudicial del Tribunal Supremo polaco y en un asunto en que se impugnaba la decisión de la autoridad polaca de la competencia. A juicio del Tribunal de Justica solo la Comisión Europea es competente para adoptar una decisión que declare que no se ha vulnerado el artículo 102 TFUE, mientras que las autoridades nacionales pueden, en su caso, decidir que no procede su intervención.

El litigio surge por la distinta interpretación del Reglamento (CE) n. ${ }^{\circ} 1 / 2003$ que dieron la autoridad administrativa polaca de la competencia y los tribunales polacos hasta llegar al Tribunal Supremo que decide el reenvío prejudicial.

En su interpretación del Reglamento el Tribunal de Justicia parte de un principio básico conforme al cual: «para garantizar una aplicación coherente de las normas de competencia en los Estados miembros, el Reglamento instaura un mecanismo de cooperación entre la Comisión y las auto- 
ridades nacionales de competencia, derivado del principio de cooperación leal» (apartado 26). De este modo, el Tribunal de Justicia considera que corresponde a los poderes de la Comisión Europea tomar las decisiones negativas, es decir, aplicar el artículo 102 TFUE y decidir que no se constata abuso de posición dominante.

Por tanto, el Tribunal de Justicia considera: «Facultar a las autoridades nacionales de competencia para tomar decisiones por las que se declare que no hay vulneración del artículo 102 TFUE cuestionaría el sistema de cooperación establecido por el Reglamento y lesionaría las competencias de la Comisión» (apartado 27). Y, seguidamente, insiste el Tribunal: «tal decisión «negativa» sobre el fondo podría menoscabar la aplicación uniforme de los artículos 101 TFUE y 102 TFUE, que es uno de los objetivos que el Reglamento pone de relieve en su primer considerando, ya que una decisión como esa podría impedir a la Comisión emitir la declaración posterior de que dicha práctica es una infracción de los citados preceptos del Derecho de la Unión» (apartado 28).

Por lo que el Tribunal de Luxemburgo concluye: «se desprende tanto del tenor como de la estructura del Reglamento, así como del objetivo que persigue, que las declaraciones de inexistencia de vulneración del artículo 102 TFUE están reservadas a la Comisión, aun cuando dicho artículo se aplique en un procedimiento instruido por una autoridad nacional de competencia» (apartado 29).

\section{La libre circulación de servicios y los decodificadores de televisión (sentencia Football Association Premier League)}

La sentencia Football Association Premier League hace un repaso del Derecho de la Unión aplicable a la retransmisión de partidos de fútbol por televisión. Los dos problemas más relevantes se refieren a la legalidad de la importación y uso de decodificadores procedentes de otros países de la Unión Europea, en este caso de Grecia, y a la difusión pública en un establecimiento de restauración en Londres de los partidos de la Liga inglesa cuya emisión se había acordado restringir a otros países de la Unión.

La sentencia es especialmente prolija y compleja, por lo que bastará con referirse a dos cuestiones: por una parte, el alcance de la libre prestación de servicios, y, por otra parte, los límites a la explotación y a la protección de los derechos de autor.

En primer lugar y por lo que se refiere a los decodificadores que permiten el acceso a las retransmisiones deportivas pero que están restringidas a determinadas zonas geográficas, el Tribunal de Justicia considera: «la normativa nacional [que] prohíbe la importación, la venta y la utilización en 
territorio nacional de decodificadores extranjeros, que permiten el acceso a los servicios de radiodifusión vía satélite procedentes de otro Estado miembro» es contraria a las libertades económicas fundamentales (apartado 89) sin que esté justificada, por ejemplo, «por razones imperiosas de interés general consistentes en la protección de derechos de propiedad intelectual» ni «con el objetivo de incentivar la presencia de público en los estadios de fútbol». Más precisamente, el Tribunal de Justicia señala que la libre prestación de servicios «debe interpretarse en el sentido de que se opone a una normativa de un Estado miembro que convierte en ilegales la importación, la venta y la utilización en ese Estado de decodificadores extranjeros que permiten el acceso a un servicio codificado de radiodifusión vía satélite procedente de otro Estado miembro que comprende los objetos protegidos por la normativa del primer Estado» (apartado 125).

En segundo lugar y respecto de los derechos de propiedad intelectual, el Tribunal de Justicia lleva a cabo un examen desde la perspectiva del Derecho de la competencia. A tal efecto, el Tribunal reformula la cuestión en estos términos: «si las cláusulas de un contrato de licencia exclusiva celebrado entre un titular de derechos de propiedad intelectual y un organismo de radiodifusión constituyen una restricción de la competencia prohibida por el artículo 101 TFUE, dado que imponen a dicho organismo la obligación de no suministrar decodificadores que den acceso en el exterior del territorio cubierto por el contrato de licencia en cuestión a los objetos protegidos de ese titular» (apartado 134). Y la respuesta es positiva (apartado 146) en la medida en que «los contratos cuyo objetivo es la compartimentación de los mercados nacionales con arreglo a las fronteras nacionales o que dificultan la interpenetración de los mercados nacionales deben considerarse, en principio, acuerdos cuyo objetivo es restringir la competencia en el sentido del artículo 101 TFUE, apartado 1» (apartado 139).

En fin, el Tribunal de Justicia se refiere al concepto de «comunicación al público» a los efectos de la Directiva sobre los derechos de autor en el caso de la transmisión de las obras difundidas, mediante una pantalla de televisión y altavoces, a los clientes presentes en un establecimiento de restauración. Ahora bien, el Tribunal de Justicia concluye que «la Directiva sobre la radiodifusión vía satélite no establece más que una armonización mínima de ciertos aspectos de la protección de los derechos de autor y de los derechos afines en caso de comunicación al público vía satélite o de distribución por cable de emisiones procedentes de otros Estados miembros [por lo que] a diferencia de lo que sucede con la Directiva sobre los derechos de autor, estas normas de armonización mínima no proporcionan elementos para determinar la licitud de los actos de reproducción realizados en la memoria de un decodificador de la señal vía satélite y en una pantalla de televisión» (apartado 209). 


\section{El acceso a la profesión de notario y la prohibición de discriminación por razón de la nacionalidad}

El acceso a la profesión de notario está abierto a los ciudadanos de la Unión tal como lo ha constatado el Tribunal de Justicia en cinco sentencias de 24 de mayo de 2011 en las que declara el incumplimiento de Bélgica, Luxemburgo, Francia, Italia, Alemania y Grecia.

En estas sentencias el Tribunal de Justicia considera que al imponer un requisito de nacionalidad para acceder a la profesión de notario se ha vulnerado el derecho de establecimiento tal como lo consagraba el art. 43 Tratado CE, el vigente art. 49 TFUE, sin que fuese aplicable ninguna excepción del art. 45 Tratado CE (vigente artículo 51 TFUE).

En su sentencia el Tribunal de Justicia subraya que el derecho de establecimiento se consagra en una de las disposiciones fundamentales del Derecho de la Unión y seguidamente recuerda que se trata de un concepto muy amplio que «implica la posibilidad de que un nacional de la Unión participe, de forma estable y continua, en la vida económica de un Estado miembro distinto de su Estado miembro de origen, y de que se beneficie de ello, favoreciendo así la interpenetración económica y social en el interior de la Unión Europea en el ámbito de las actividades por cuenta propia».

A tal efecto, el Tribunal de Justicia analiza el alcance del concepto de ejercicio del poder público y si las actividades encomendadas a los notarios en los distintos ordenamientos nacionales encajan en ese concepto. Por ejemplo y respecto del Derecho belga el Tribunal de Justicia considera que las siguientes funciones notariales no están relacionadas con el ejercicio del poder público en el sentido de la excepción prevista al derecho de establecimiento tal como lo consagra el Tratado constitutivo: autenticación de documentos, ejecución de embargos de bienes inmuebles, ventas de inmuebles, formación del inventario de sucesiones, colocación y levantamiento de precintos, división judicial de bienes, formalización en documento notarial, bajo pena de nulidad, de determinados negocios jurídicos como las donaciones inter vivos, los testamentos, las capitulaciones matrimoniales y los contratos que rigen la situación de las parejas de hecho, o la constitución de sociedades y fundaciones, ni la recaudación de determinados impuestos (apartado 123).

En cambio, el Tribunal de Justicia considera que estos países no incumplieron la Directiva 89/48/CE al no transponer sus obligaciones precisamente respecto de la profesión de notario pues como señala el Tribunal: «habida cuenta de las circunstancias particulares presentes en el proceso legislativo y de la situación de incertidumbre que éstas provocaron, tal como se desprende del contexto legislativo descrito anteriormente, no resulta posible declarar que, en la fecha en que expiró el plazo señalado en el dicta- 
men motivado, existía una obligación suficientemente clara que impusiera a los Estados miembros la transposición de la Directiva 89/48/CE en relación con la profesión de notario» (apartado 141 de la sentencia declarativa del incumplimiento de Bélgica).

\section{Tercera parte. La jurisprudencia del tribunal de justicia y el derecho español}

En España se recordará 2011 por haber sido el año en que por primera vez el Tribunal Constitucional acudió por vía prejudicial al Tribunal de Justicia para plantearle no solo cuestiones de interpretación sino también sobre la validez de la regulación europea de la euroorden en relación con la garantía del derecho fundamental a la tutela judicial efectiva. Por lo demás, especialmente en cuanto a los reenvíos prejudicial planteados por jueces españoles y respecto de las sentencia del Tribunal de Justicia que contesta reenvíos prejudiciales hechos por lo general en 2010 se puede considerar un año especialmente significativo y que refleja la tónica general de nuestros tribunales en que, de manera especial, la jurisdicción contencioso-administrativa es la más interesada en la interpretación del Derecho de la Unión, seguida por una dinámica actitud de los tribunales de lo social y, en menor medida, de los tribunales especializados en materia mercantil. En fin, terminó con tres sentencias que referidas al cumplimiento por España del Derecho de la Unión en ámbitos como el establecimiento de grandes superficies comerciales, el urbanismo valenciano y la emisión de publicidad en las televisiones.

\section{Los reenvíos prejudiciales de los jueces españoles: la primera cuestión prejudicial del Tribunal Constitucional (asunto Melloni)}

Por emplear la conocida expresión de la profesora Mangas Martín, el Tribunal Constitucional español ha superado la «barrera psicológica» que le suponía plantear cuestiones prejudiciales. Resultaba claro que, tarde o temprano y debido a las funciones encomendadas al Tribunal Constitucional, especialmente de interpretación y garantía de los derechos fundamentales, tendría que recurrir a la cooperación y al diálogo con el Tribunal de Justicia.

La primera petición prejudicial la realiza el Tribunal Constitucional en su auto, de 9 de junio de 2011, dictado por el pleno y con un voto particular en contra, en un asunto en que un nacional italiano, Stefano Melloni, que había sido condenado en su país penalmente y en rebeldía por quiebra fraudulenta, es reclamado por una orden europea de extradición y entrega remi- 
tida por los tribunales italianos y autorizada por la Audiencia Nacional (C194/11, Melloni).

Al acceder en amparo ante el Tribunal Constitucional, este se plantea la aplicación de una jurisprudencia anterior conforme a la cual la decisión de un órgano judicial español, de acceder a la entrega incondicionada para cumplimiento de condenas graves dictadas en ausencia del reclamado en el marco del procedimiento de extradición, vulneraría el derecho a un proceso con todas las garantías y, en particular, el derecho a la defensa. Ahora bien, el Tribunal Constitucional español es consciente de que esa jurisprudencia se enfrenta a la Decisión Marco 2002/584/JAI sobre la orden europea de detención y entrega, que, en el aspecto controvertido, fue modificada por la Decisión Marco 2009/299/JAI.

En un auto de planteamiento de la cuestión prejudicial técnicamente impecable, aun cuando resulte a mi juicio excesivamente profesoral, el Tribunal Constitucional español esboza primero el marco jurídico del Derecho de la Unión aludiendo a la regulación de la euroorden y a la aplicación en este supuesto de la Carta de Derechos Fundamentales de la Unión así como del Convenio Europeo de Derechos Humanos.

En ese contexto el Tribunal Constitucional español solicita, en primer lugar, una interpretación de la Decisión Marco para saber si permite a los jueces nacionales someter la ejecución de una orden europea de detención y entrega a la condición de que la condena en cuestión pueda ser revisada para garantizar los derechos de defensa del reclamado. Subsidiariamente, el Tribunal Constitucional plantea una cuestión de validez para saber si la Decisión Marco es contraria a los derechos a la tutela judicial efectiva y a un proceso equitativo tal como están previstos en la Carta de la Unión. Por último, el Tribunal Constitucional interroga al Tribunal de Justicia sobre la interpretación del artículo 53 de la Carta para saber cómo se articula la protección de los derechos fundamentales de conformidad con la Carta y con las tradiciones constitucionales nacionales, y más en particular para conocer si la protección asegurada por la Unión Europea es de mínimos o de máximos.

El voto particular está formulado por el que podría considerarse como el más europeísta de nuestros magistrados constitucionales, Pablo Pérez Tremps, y en el mismo destaca su complacencia en que el Tribunal Constitucional haya acudido al Tribunal de Justicia aunque desaconseja que se hiciese en este caso o, el menos, en los términos en que se ha hecho. Probablemente, el argumento más demoledor del voto discrepante se funda en la consideración de que «la confianza legítima horizontal, recíproca, en el sistema de reconocimiento y garantía de los derechos fundamentales de otro Estado cobra especial significado en un mecanismo jurídico como es el de la orden europea de detención y entrega». 
El planteamiento de la cuestión prejudicial por el Tribunal Constitucional es una continuación y un complemento de la cuestión prejudicial planteada por la Corte Constitucional belga que está en el origen de la sentencia, de 21 de octubre de 2010, I.B. (C-306/09) donde el Tribunal de Justicia señalaba: «Aunque el principio de reconocimiento mutuo subyace al sistema de la Decisión marco 2002/584, este reconocimiento no implica sin embargo, como se desprende de sus artículos 3 a 5, una obligación absoluta de ejecución de la orden de detención dictada» (apartado 50); que, sin embargo, no interpretaba la modificación de la Decisión Marco de 2009 aplicable a las resoluciones dictadas a partir del 28 de marzo de 2011 sin la presencia durante el proceso de la persona afectada.

Los demás reenvíos prejudiciales españoles de 2011 proceden, especialmente, de los tribunales contencioso-administrativos donde, un año más, destacan las cuestiones prejudiciales formuladas por el Tribunal Supremo respecto del control de legalidad de normas reglamentarias, fundamentalmente Reales Decretos. Precisamente y en este ámbito destacan las prejudiciales planteadas respecto de la conformidad con la Directiva 2002/20/CE relativa a la autorización de redes y servicios de comunicaciones electrónicas de numerosísimas ordenanzas municipales que impone una tasa por derechos de instalación de recursos sobre el dominio público municipal a las empresas operadoras que, sin ser titulares de la red, la usan para prestar servicios de telefonía móvil (C-55/11, Vodafone España; C-57/11, Vodafone España; y C-58/11, France Telecom España). También procede de la Sala de lo Contencioso-administrativo del Tribunal Supremo el reenvío prejudicial relativo a la cooperación administrativa, entre las autoridades españolas y gibraltareñas, en materia de blanqueo de capitales (C-212/11, Jyske Bank Gibraltar). En fin, el Tribunal Supremo ha planteado la cuestión relativa a la interpretación de la Directiva 2003/87/CE sobre el comercio de derechos de emisión de gases de efecto invernadero en relación con su aplicación normativa en España, a través del un Real Decreto-ley y de una orden ministerial (C-567/11, Gas Natural).

Asimismo, la Sala de lo Contencioso-administrativo del Tribunal Superior de Justicia de Cataluña ha planteado una cuestión prejudicial en relación con el IVA aplicable a los juegos de azar (International Bingo Technology, C-377/11). Por último deben destacarse las cuestiones prejudiciales formuladas por el Juzgado de lo Contencioso-administrativo n. ${ }^{\circ} 1$ de Oviedo en relación con el disfrute de vacaciones durante la incapacidad transitoria de los funcionarios de la Administración de Justicia (C-99/11, Natividad Martínez Álvarez / Principado de Asturias) y del Juzgado de lo Contencioso-administrativo n. ${ }^{\circ} 4$ de Valladolid sobre la percepción de los «sexenios de formación» únicamente por los profesores de enseñanza no universitaria que sean funcionarios de carrera (C-556/11, M. ${ }^{a}$ Jesús Lorenzo Martínez/Junta de Castilla y León). 
En el ámbito social, el Tribunal Supremo ha planteado una interesantísima cuestión que afectará sin duda a su propia jurisprudencia en relación también con el disfrute de las vacaciones por los trabajadores en situación de incapacidad laboral (C-78/11, ANGED). La Sala de lo Social del Tribunal Superior de Justicia de Galicia ha planteado una cuestión prejudicial relativa a la aplicación de los Reglamentos comunitarios sobre Seguridad Social (C-282/11, Salgado González). Asimismo, el Juzgado de lo Social n. 33 de Barcelona le ha preguntado al Tribunal de Justicia sobre la interpretación del régimen de jubilación aplicable a los trabajadores a tiempo parcial (C-385/11, Elbal Moreno).

En fin, en el ámbito civil y mercantil, los litigios de los pasajeros del transporte aéreo están en el origen de las cuestiones prejudiciales enviadas en 2011 a Luxemburgo por el Juzgado de lo Mercantil n. ${ }^{\circ} 2$ de A Coruña (C-321/11, Rodríguez Cachafeiro y otros / Iberia) y por la Audiencia Provincial de Barcelona (C-410/11, Espada Sánchez y otros / Iberia). El tribunal gallego pregunta sobre la interpretación del concepto de denegación de embarque, en particular si puede considerarse denegación de embarque que la compañía aérea deniegue el embarque porque el primer trayecto del billete sufre un retraso imputable a ella y prevea erróneamente que los pasajeros no llegarán a tiempo al segundo vuelo, en el que permite que las plazas de estos sean ocupadas por otros pasajeros. Y el tribunal catalán inquiere al Tribunal de Justicia sobre los límites de la indemnización que corresponde a cada pasajero y a cada bulto facturado.

\section{Las sentencias dictadas por el Tribunal de Justicia en respuesta a reenvios prejudiciales de los tribunales españoles}

Las sentencias pronunciadas por el Tribunal de Justicia en 2011 en cuestiones prejudiciales españolas ofrecen un panorama que se repite en los últimos años. Por una parte, los tribunales contencioso-administrativos son los que más sentencias generan, siete en 2011, especialmente el Tribunal Supremo de la conformidad de los numerosísimos Reales Decretos que se adoptan para transponer las directivas al Derecho español. Del mismo modo, los jueces de lo social preguntan sobre temas muy vinculados a la discriminación en el empleo y a la aplicación de la legislación social europea y se reflejan en las dos sentencias de 2011 del Tribunal de Justicia; una sentencia del Tribunal de Justicia responde a un Juzgado de lo Mercantil sobre la interpretación del Reglamento sobre protección de los viajeros de avión; y, por último, es poco frecuente que el Tribunal de Justicia responda con una sentencia a una Audiencia Provincial en el ámbito de la cooperación policial y judicial penal, en este caso con el fin de acla- 
rar el estatuto penal de la víctima en un proceso penal por violencia de género.

A. Las sentencias en materia contencioso-administrativo: tributos, derecho a la privacidad y antiguiedad como funcionario interino

Seis de las 11 sentencias pronunciadas por el Tribunal de Justicia en respuesta a reenvíos prejudiciales españoles en 2011 contestan las preguntas de la Sala de lo Contencioso-administrativo del Tribunal Supremo: Telefónica Móviles España, Telefónica de España, Campsa Estaciones de Servicio, Unió de Pagesos de Catalunya, ASNEFF y Banco Bilbao Vizcaya Argentaria.

La sentencia Telefónica Móviles España (C-85/10) y la sentencia Telefónica de España (C-284/10) interpretan la Directiva 97/13/CE relativa a un marco común en materia de autorizaciones generales y licencias individuales en el ámbito de los servicios de telecomunicaciones.

En la sentencia Telefónica Móviles España el Tribunal de Justicia se pronuncia sobre la liquidación girada respecto de 2001 en concepto de tasa por reserva del dominio público radioeléctrico.

En este caso el Tribunal de Justicia interpreta el artículo 11 de la Directiva 97/13 de modo que, al compararlo con la tasa española, llega a la conclusión de la conformidad de esta en la medida en que es «un gravamen por el uso de radiofrecuencias a los operadores de servicios de telecomunicaciones titulares de licencias individuales sin asignar una finalidad específica a los ingresos obtenidos de ese gravamen, y que incrementa significativamente el importe del gravamen para una determinada tecnología sin modificarlo para una tecnología distinta» (apartado 40).

La sentencia Telefónica de España se pronuncia sobre la tasa en el servicio de las telecomunicaciones. Telefónica pretendía que la liquidación de la tasa por la titularidad de autorizaciones generales y licencias individuales para la prestación de servicios de telecomunicaciones a terceros girada en 2000 fuese considerada contraria a la Directiva 97/13/CE. Sin embargo, el Tribunal de Justicia considera que, en principio, una tasa como la exigida en España es conforme con la Directiva, aunque precisa que debe cumplir estas característica: «una tasa que se calcula con periodicidad anual sobre la base de los ingresos brutos de explotación de los operadores sujetos a ella y que se destina a sufragar los gastos administrativos relacionados con los procedimientos de expedición, gestión, control y ejecución de dichas autorizaciones, siempre que el total de los ingresos obtenidos por el Estado miembro en virtud de dicha tasa no exceda del total de los gastos administrativos mencionados» (apartado 36).

La sentencia Campsa Estaciones de Servicio también la pronuncia el Tribunal de Justicia a instancia del Tribunal Supremo español y versa so- 
bre la base imponible del IVA en el caso de las operaciones entre partes vinculadas: la transmisión en 1993 de Campsa a Repsol de varias estaciones de servicio.

La respuesta del Tribunal de Justicia pone en evidencia la legislación fiscal española dado que la Directiva impide que una regla de determinación de la base imponible distinta de la regla general se aplique a operaciones realizadas entre partes vinculadas mediando un precio notoriamente inferior al normal de mercado. Y la razón de tal solución es que España no había conseguido la autorización para inaplicar la regla general.

En el asunto Unió de Pagesos de Catalunya el Tribunal Supremo tenía que resolver la impugnación directa del Real Decreto 1470/2007 sobre aplicación de los pagos directos a la agricultura y a la ganadería. A tal efecto, consideró que era relevante confrontarlo con el Reglamento (CE) n. ${ }^{\circ} 1782 / 2003$ sobre regímenes de ayuda a los agricultores y más en particular por cuanto condiciona la posibilidad de obtener derechos de pago único de la reserva nacional a que se trate de agricultores jóvenes que hayan realizado su primera instalación en el ámbito de un programa de desarrollo rural. Ahora bien, el Tribunal de Justicia ante la objeción del abogado del Estado español de que el Real Decreto enjuiciado había sido derogado por el Real Decreto 1612/2008 pronunció la sentencia Unió de Pagesos de Catalunya que inadmite el reenvío prejudicial al considerarla una «cuestión de naturaleza hipotética». En cambio, la abogada general Juliane Kokott, si bien con ciertas reservas, se pronunció sobre el fondo considerando que la regulación española no era contraria al Derecho de la Unión.

La sentencia ASNEFF y Marketing Directo contesta un reenvío prejudicial del Tribunal Supremo y se pronuncia sobre el alcance del derecho a la protección de datos personales. El reenvío prejudicial del Tribunal Supremo pretendía aclarar, en el control de legalidad que lleva a cabo el Tribunal español del Reglamento de protección de datos respecto de la Directiva 95/46/ CE. Como resume el propio Tribunal de Justicia se trata de saber si el artículo la Directiva es compatible con el Real Decreto que, para permitir el tratamiento de datos personales necesario para la satisfacción del interés legítimo perseguido por el responsable del tratamiento o por el tercero o terceros a los que se comuniquen los datos, exige, en el caso de que no exista consentimiento del interesado, no solo que se respeten los derechos y libertades fundamentales de éste, sino además que dichos datos figuren en fuentes accesibles al público.

En este caso, el Tribunal de Justicia contesta, por una parte: «el artículo 7, letra f), de la Directiva 95/46 debe interpretarse en el sentido de que se opone a una normativa nacional que, para permitir el tratamiento de datos personales necesario para la satisfacción del interés legítimo perseguido por el responsable del tratamiento o por el tercero o terceros a los 
que se comuniquen los datos, exige, en el caso de que no exista consentimiento del interesado, no solo que se respeten los derechos y libertades fundamentales de éste, sino además que dichos datos figuren en fuentes accesibles al público, excluyendo así de forma categórica y generalizada todo tratamiento de datos que no figuren en tales fuentes» (apartado 49). Y al mismo tiempo reconoce el efecto directo del referido artículo 7.c) de la Directiva 95/46/CE.

Precisamente, el Tribunal de Justicia define el alcance del efecto directo: «según reiterada jurisprudencia del Tribunal de Justicia, siempre que las disposiciones de una directiva resulten ser, desde el punto de vista de su contenido, incondicionales y suficientemente precisas, los particulares podrán invocarlas frente al Estado, en particular cuando éste no haya adaptado el Derecho nacional a la Directiva dentro del plazo señalado o cuando haya procedido a una adaptación incorrecta» (apartado 51).

La primera idea que late en la sentencia es que: «el respeto del derecho a la vida privada en lo que respecta al tratamiento de los datos de carácter personal, reconocido por los artículos 7 y 8 de la Carta, se aplica a toda información sobre una persona física identificada o identificable pero también de la Carta se desprende que, bajo ciertas condiciones, pueden introducirse limitaciones a dicho derecho (apartado 42).

Y la segunda idea consiste en que «los tratamientos de datos que figuran en fuentes no accesibles al público implican necesariamente que el responsable del tratamiento y, en su caso, el tercero o terceros a quienes se comuniquen los datos dispondrán en lo sucesivo de ciertas informaciones sobre la vida privada del interesado. Esta lesión, más grave, de los derechos del interesado consagrados en los artículos 7 y 8 de la Carta debe ser apreciada en su justo valor, contrapesándola con el interés legítimo perseguido por el responsable del tratamiento o por el tercero o terceros a los que se comuniquen los datos». Por tanto y si bien los Estados pueden establecer los principios que deben regir dicha ponderación, lo que no pueden hacer es adoptar una normativa nacional que excluya la posibilidad de tratar determinadas categorías de datos personales, estableciendo con carácter definitivo el resultado de la ponderación de los derechos e intereses en conflicto respecto de tales categorías, sin permitir un resultado diferente en atención a las circunstancias particulares de cada caso concreto (apartados 45 a 47).

En fin, en la sentencia Banco Bilbao Vizcaya Argentaria el Tribunal de Justicia le explica al Tribunal Supremo español el alcance de la libre circulación de capitales y del régimen de doble imposición. En este caso la cuestión radicaba en si el BBVA podía deducir en el ejercicio fiscal de 1991 respecto del impuesto sobre sociedades declarado en España la cuota devengada en Bélgica por los intereses obtenidos a pesar de que no pagó la cuota por estar exenta. 
El Tribunal de Justicia precisa que la legislación aplicable es la vigente en 1991, antes de adoptarse la legislación de la moneda única europea. Ahora bien, el Tribunal de Justicia llega a la conclusión de que la legislación española era conforme con la legislación comunitaria europea aplicable. A tal efecto, el Tribunal de Justicia señala: «los intereses abonados por un deudor establecido en otro Estado miembro pueden ser objeto de doble imposición jurídica cuando los dos Estados miembros deciden ejercer su potestad tributaria y someter dichos intereses a imposición, el primer Estado aplicando a los mismos una retención en la fuente y el segundo incluyéndolos en los rendimientos imponibles del beneficiario» (apartado 30). Ciertamente, como subraya el Tribunal de Justicia, «al no existir medidas de unificación o de armonización de la Unión, los Estados miembros siguen siendo competentes para fijar, mediante convenio o de forma unilateral, los criterios de reparto de la potestad tributaria con el fin, en particular, de suprimir la doble imposición [y] les corresponde adoptar las medidas necesarias para evitar situaciones de doble imposición, en particular, utilizando los criterios seguidos en la práctica tributaria internacional» (apartado 31). Sin embargo y en el caso concreto así parece que era la situación del BBVA: «las desventajas que pueden resultar del ejercicio paralelo por diferentes Estados miembros de la potestad tributaria, siempre y cuando tal ejercicio no sea discriminatorio, no constituyen restricciones de las libertades de circulación» (apartado 38).

Ya en otro ámbito, la sentencia Rosado Santana / Junta de Andalucía constituye la respuesta a un reenvío prejudicial del Juzgado de lo Contencioso-administrativo $n .{ }^{\circ} 12$ de Sevilla que le plantea el problema del cómputo de la experiencia profesional adquirida como funcionario interino. En este caso, un funcionario de carrera de la Administración andaluza pretendía que se le tuviesen en cuenta, a los efectos de promoción profesional, diez años de antigüedad adquiridos previamente como funcionario interino.

Pues bien y en este caso frente a las alegaciones de las Administraciones, incluida la Comisión Europea, el Tribunal de Justicia señala: «las normas nacionales relativas a los períodos de servicio que deben cumplirse para poder ser clasificado en una categoría retributiva superior o a fines del cálculo de los períodos de servicio requeridos para ser objeto de un informe de calificación cada año y, en consecuencia, poder beneficiarse de una promoción profesional como la controvertida en el litigio principal forman parte integrante de las condiciones de trabajo» (apartado 46).

Y a partir de ahí el Tribunal de Justicia, frente a la sugerencia del Tribunal sevillano de que el Tribunal Constitucional consideraba justificada la diferencia establecida entre funcionarios de carrera y funcionarios interinos, lanza esta advertencia: «En el supuesto de que un tribunal nacio- 
nal, incluido un tribunal constitucional, excluyera la aplicación de la Directiva 1999/70/CE y del Acuerdo marco al personal de la función pública de un Estado o permitiera diferencias de trato entre los funcionarios interinos y los funcionarios de carrera a falta de razones objetivas, en el sentido de la cláusula 4, apartado 1, de dicho Acuerdo marco, procederá declarar que tal jurisprudencia va en contra de lo dispuesto en estas normas del Derecho de la Unión e incumple las obligaciones que incumben a las autoridades judiciales de los Estados miembros, en el marco de sus competencias, de garantizar la protección jurídica que de las disposiciones de dicho Derecho se desprende para los justiciables y de garantizar su pleno efecto» (apartado 61). Y concluye el Tribunal de Justicia con esta interpretación: «la Directiva 1999/70/CE y el Acuerdo marco que figura en el anexo de ésta deben interpretarse en el sentido de que, por un lado, se aplican a las relaciones de servicio de duración determinada y a los contratos celebrados por los órganos de la Administración y el resto de entidades del sector público, $y$, por otro, exigen que se excluya toda diferencia de trato entre los funcionarios de carrera y los funcionarios interinos comparables de un Estado miembro basada en el mero hecho de que éstos tienen una relación de servicio de duración determinada, a menos que razones objetivas, en el sentido de la cláusula 4, apartado 1, de dicho Acuerdo marco, justifiquen un trato diferente» (apartado 62).

En fin, el Tribunal de Justicia profundiza en la posibilidad de que haya razones objetivas para establecer diferencias entre los distintos tipos de funcionarios; sin embargo, llega a esta conclusión: «la cláusula 4 del Acuerdo marco debe interpretarse en el sentido de que se opone a que los períodos de servicio cumplidos por un funcionario interino de una Administración Pública no sean tenidos en cuenta para el acceso de éste, que entre tanto ha tomado posesión como funcionario de carrera, a una promoción interna en la que sólo pueden participar los funcionarios de carrera, a menos que dicha exclusión esté justificada por razones objetivas, en el sentido del apartado 1 de dicha cláusula. El mero hecho de que el funcionario interino haya cumplido dichos períodos de servicio sobre la base de un contrato o de una relación de servicio de duración determinada no constituye tal razón objetiva» (apartado 84).

Precisamente en la sentencia Rosado Santana el Tribunal de Justicia examina y relativiza una jurisprudencia española muy asentada sobre la inimpugnabilidad de las convocatorias relativas a la selección y a la promoción de empleados públicos que sean firmes y consentidas por no haber sido impugnadas en plazo. A tal efecto, el Tribunal de Justicia argumenta: «el Derecho primario de la Unión, la Directiva 1999/70/CE y el Acuerdo marco deben interpretarse en el sentido de que no se oponen, en principio, a una norma nacional que prevé que el recurso interpuesto por un funciona- 
rio de carrera contra una resolución por la que se le excluye de un proceso selectivo y basado en que dicho proceso era contrario a la cláusula 4 de dicho Acuerdo marco debe interponerse en un plazo preclusivo de dos meses desde la fecha de la publicación de la convocatoria. Sin embargo, tal plazo no podía oponerse a un funcionario de carrera, candidato a dicho proceso selectivo, que fue admitido al mismo y cuyo nombre figuraba en el listado definitivo de aprobados de dicho proceso, si podía hacer imposible o excesivamente difícil el ejercicio de los derechos conferidos por el Acuerdo marco. En tales circunstancias, el plazo de dos meses sólo podría empezar a correr desde la notificación de la resolución por la que se anulaba su admisión a dicho proceso y su nombramiento como funcionario de carrera del grupo superior» (apartado 100).

\section{B. Las sentencias en materia social: garantía por traspaso de empresas y protección de riesgos laborales}

En el ámbito de la jurisdicción social, el Tribunal de Justicia responde con la sentencia CLECE a las dudas sobre el mantenimiento de los derechos de los trabajadores en caso de la transmisión de una empresa a un ayuntamiento; con la sentencia Barcenilla Fernández se pronuncia sobre la eficacia de la Directiva sobre la protección de los trabajadores contra el ruido; y con el auto Montoya Medina sobre la Directiva 1999/70/CE sobre el trabajo de duración determinada y el reconocimiento de trienios al personal docente universitario laboral.

La sentencia CLECE responde el reenvío de la Sala de lo Social del Tribunal Superior de Justicia de Castilla-La Mancha en un litigio que tiene su origen en la disputa entre la empresa CLECE, que había prestado servicios de limpieza en los colegios y dependencias municipales para el Ayuntamiento toledano de Cobisa, y que pretendía que al término del contrato de servicios el Ayuntamiento se había subrogado en la relación laboral con una de las trabajadoras de la empresa.

El Tribunal de Justicia precisa, en primer lugar, que puede estar comprendida en el ámbito de aplicación de la Directiva una situación en la que una empresa, que se sirve de otra empresa para la limpieza de sus locales, decide resolver el contrato y ejecutar por sí misma esas tareas. Sin embargo, para que la Directiva sea aplicable, la transmisión debe tener por objeto una entidad económica que mantenga su identidad tras el cambio de titular por lo que en el supuesto concreto no se aplica a una situación en la que un ayuntamiento, que había encargado la limpieza de sus dependencias a una empresa privada, decide poner fin al contrato celebrado con ésta y realizar por sí mismo los trabajos de limpieza de dichas dependencias, contratando para ello nuevo personal (apartado 43). 
La sentencia Barcenilla Fernández se refiere al efecto que puede llegar a tener en las retribuciones de los trabajadores una Directiva sobre protección frente al ruido. En este asunto dos trabajadores habían demandado ante el Juzgado de lo Social a su empresario para que les abonase un complemento salarial de penosidad de su puesto de trabajo por estar expuestos a un nivel de ruido que supera el promedio diario determinado. Frente a la desestimación del Juzgado acudieron en suplicación a la Sala de lo Social del Tribunal Superior de Justicia de Castilla y León que acudió a Luxemburgo.

A juicio del Tribunal de Justicia la Directiva sobre la protección de los trabajadores contra el ruido no regula el pago de un complemento salarial por razón de la penosidad de un puesto de trabajo derivada de la exposición al ruido, ni la cuestión de si puede o debe tenerse en cuenta el efecto de una protección auditiva individual para determinar el umbral de exposición al ruido que da lugar a la obligación de pagar el referido complemento salarial. Sin embargo, el Tribunal de Justicia hace una puntualización conforme a la cual: «el Derecho nacional debe establecer mecanismos adecuados que garanticen que un trabajador expuesto a un nivel de ruido superior a $85 \mathrm{~dB}(\mathrm{~A})$, medido sin tener en cuenta los efectos de la utilización de protectores auditivos individuales, pueda invocar el cumplimiento, por el empresario, de las obligaciones preventivas establecidas en el artículo 5, apartado 2, de dicha Directiva» (apartado 43).

Esta interpretación está alentada por la jurisprudencia Marleasing que en este caso el Tribunal de Justicia enuncia así: «es preciso recordar la reiterada jurisprudencia según la cual la libertad en la elección de los procedimientos y los medios destinados a garantizar la aplicación de una directiva no menoscaba la obligación de los Estados miembros destinatarios de aquélla de adoptar todas las medidas necesarias para garantizar la plena eficacia de la directiva, conforme al objetivo por ella perseguido [...], y de garantizar, en el caso de que la directiva de que se trate tenga por objeto crear derechos para los particulares, que éstos estén en condiciones de invocarlos, en su caso, ante los órganos jurisdiccionales nacionales» (apartado 41).

Esta última precisión permitió a la Sala de lo Social de Castilla y León pronunciar la sentencia estimatoria por la que reconocía a los dos trabajadores la cuantía del complemento retributivo reclamado.

Por último, el auto Montoya Medina aplica, a instancias de la Sala de lo Social del Tribunal Superior de Justicia de Valencia, la jurisprudencia del Tribunal de Justicia en sentencias bien conocidas, de 13 de septiembre de 2007, Del Cerro Alonso (C-307/05), de 15 de abril de 2008, Impact (C-268/06), y de 22 de diciembre de 2010, Gavieiro Gavieiro e Iglesias Torres (C-444/09 y C-456/09) a la discriminación entre personal laboral de las universidades públicas. 
Por tanto y a juicio del Tribunal de Justicia, es contraria a la Directiva 1999/70/CE sobre el trabajo de duración determinada «una normativa nacional que reserva, sin ninguna justificación objetiva, el derecho a percibir un complemento salarial por antigüedad únicamente a los profesores contratados doctores, excluyendo a los profesores ayudantes doctores, cuando, en relación con la percepción de dicho complemento, ambas categorías de trabajadores se hallan en situaciones comparables».

\section{La sentencia en el ámbito civil (mercantil) sobre usuarios del transporte aéreo}

Con la sentencia Sousa Rodríguez el Tribunal de Justicia responde un reenvío prejudicial del Juzgado de lo Mercantil n. ${ }^{\circ} 1$ de Pontevedra sobre la interpretación del Reglamento (CE) n. ${ }^{\circ}$ 261/2004 sobre compensación y asistencia a los pasajeros aéreos en caso de denegación de embarque y de cancelación o gran retraso de los vuelos.

El litigio surgió a raíz de la demanda de varios pasajeros contra Air France que debía hacer el trayecto entre París y Vigo y pocos minutos después de despegar del avión a la hora prevista, el piloto decidió volver al punto de origen, el aeropuerto de París Charles de Gaulle, por un problema técnico de la aeronave; los pasajeros solo pudieron volar al día siguientes desde París Orly con destino a Oporto, desde donde se trasladaron a Vigo en taxi.

La primera cuestión prejudicial versa sobre el concepto de «cancelación» definido en el Reglamento. Y a juicio del Tribunal de Justicia la cancelación no se refiere exclusivamente al supuesto de que el avión de que se trate no haya despegado en modo alguno sino que incluye igualmente el supuesto de que el avión haya despegado, pero, cualquiera que sea la razón, se vea obligado a regresar al aeropuerto de origen y los pasajeros de dicho avión hayan sido transferidos a otros vuelos.

La segunda cuestión se refiere a la «compensación suplementaria», mencionada en el Reglamento y que, de acuerdo con el Tribunal de Justicia, debe interpretarse en el sentido de que «permite al juez nacional conceder, en las condiciones previstas por el Convenio de Montreal o por el Derecho nacional, indemnización de daños y perjuicios, incluidos los daños morales, por incumplimiento del contrato de transporte aéreo. En cambio, dicho concepto de «compensación suplementaria» no puede servir de fundamento jurídico al juez nacional para condenar al transportista aéreo a reembolsar a los pasajeros cuyo vuelo haya sido retrasado o cancelado los gastos que éstos hayan tenido que efectuar a causa del incumplimiento, por parte de dicho transportista, de las obligaciones de asistencia y atención previstas en los artículos 8 y 9 de este Reglamento». 
No obstante y como precisó también el Tribunal de Justicia: «no hay nada en el Reglamento $n .^{\circ}$ 261/2004 que impida conceder una compensación por un incumplimiento de los obligaciones previstas en los artículo 8 y 9 de dicho Reglamento, si estas disposiciones no han sido invocadas por los pasajeros aéreos» (apartado 45).

\section{La sentencia en materia penal y el estatuto de las víctimas de malos tratos}

La sentencia Gueye responde un reenvío prejudicial de la Audiencia Provincial de Tarragona en materia de cooperación policial y judicial en materia penal habiéndose planteado en dos procedimientos penales seguidos contra los Sres. Gueye y Salmerón por quebrantamiento de la pena accesoria de prohibición de aproximarse a sus parejas, víctimas de sendos delitos de maltrato que, sin embargo, habían consentido libremente en reiniciar la convivencia. Apelando al Derecho de la Unión, el tribunal catalán cuestionaba la tipificación del delito por concurrir la voluntad de la víctima de la violencia de género y a tal efecto se apoyaba en la interpretación de la Decisión marco 2001/220/JAI relativa al estatuto de la víctima en el proceso penal.

El Tribunal de Justicia precisó en su sentencia que contestaba por la vía especial establecida para el ámbito de la cooperación policial y judicial penal (el antiguo artículo 35.3 TUE aplicable hasta el 1 de diciembre de 2014 limita el acceso, de conformidad con el Protocolo 36 del Tratado de Lisboa y por lo que a España se refiere a tribunales cuyas decisiones no sean susceptibles de ulterior recurso judicial de Derecho interno).

En primer lugar, el Tribunal de Justicia subraya: «Las disposiciones de la Decisión marco deben interpretarse de modo que se respeten los derechos fundamentales, de entre los que es preciso destacar, en particular, el derecho al respeto de la vida privada y familiar tal como se formula en el artículo 7 de la Carta de los Derechos Fundamentales de la Unión Europea» (apartado 55).

A continuación, el Tribunal de Justicia precisa: «la protección penal contra los actos de violencia doméstica que establece un Estado miembro en ejercicio de su potestad sancionadora no sólo tiene por objeto la protección de los intereses de la víctima tal como ésta los percibe, sino también la protección de otros intereses más generales de la sociedad» (apartado 61).

Por esa razón, a juicio del Tribunal de Justicia: «los artículos 2, 3 y 8 de la Decisión marco deben interpretarse en el sentido de que no se oponen a la imposición de una medida de alejamiento preceptiva con una duración mínima, prevista como pena accesoria por el Derecho penal de un Estado miembro, a los autores de violencia en el ámbito familiar, aun en el 
supuesto de que las víctimas de esa violencia se opongan a la aplicación de tal medida» (apartado 70).

Y aporta el Tribunal de Justicia una segunda interpretación relativa a la mediación en los procedimientos penales considerando que la Decisión marco relativa al estatuto de la víctima en el proceso penal «permite a los Estados miembros, en atención a la tipología específica de las infracciones cometidas en el ámbito familiar, excluir la mediación en todos los procesos penales relativos a tales infracciones» (apartado 76).

\section{Las sentencias declarativas del incumplimiento del Reino de España (licencias, anuncios televisivos y urbanismo valenciano)}

De las ocho sentencias dictadas en 2011 en recursos por incumplimiento conviene dar cuenta solo de tres: en dos de ellas se declara el incumplimiento de España en materia de licencias de aperturas de grandes superficies y por los anuncios publicitarios en las televisiones; mientras que la otra, debido a defectos procesales imputables a la Comisión Europea, es desestimatoria en relación con la aplicación de las Directivas sobre contratos públicos a la legislación urbanística valenciana.

El Tribunal de Justicia declara, en virtud de la sentencia de 24 de marzo de 2011, la infracción por parte de España de la libertad de establecimiento al aplicar determinadas disposiciones de la Ley estatal de ordenación del comercio minorista y de la normativa catalana, en particular la Ley autonómica de equipamientos comerciales, el Decreto catalán de desarrollo de la Ley y el Decreto autonómico que aprueba el Plan territorial sectorial de equipamientos comerciales.

El origen del procedimiento por incumplimiento seguido por la Comisión Europea está en una denuncia de diversas empresas del sector de la gran distribución que permitió a la Comisión cuestionar la compatibilidad de la normativa reguladora del establecimiento de grandes superficies comerciales en Cataluña con el artículo 43 del Tratado CE, es decir, el vigente artículo 49 TFUE. Es importante subrayar que el enjuiciamiento del Tribunal de Justicia consiste única y exclusivamente en comparar la legislación española con la libertad económica fundamental, con el derecho de establecimiento reconocido en el Tratado constitutivo, sin atender a los desarrollos de la Directiva 2006/123/CE relativa a los servicios en el mercado interior; de hecho, no la menciona más que para recordar que España alegaba que estaba precisamente intentando adaptar su legislación a las exigencias de la Directiva (apartado 33 de la sentencia).

El Tribunal de Justicia examina las limitaciones en cuanto al emplazamiento y al tamaño de los grandes establecimientos comerciales, los requi- 
sitos para la obtención de la licencia comercial específica exigida para la implantación de tales establecimientos y determinados aspectos del procedimiento de concesión de dicha licencia.

En primer lugar, el Tribunal de Justicia delimita el contenido de la libertad de establecimiento proscribiendo «cualquier medida nacional que, aun cuando sea aplicable sin discriminación por razón de nacionalidad, pueda obstaculizar o hacer menos atractivo el ejercicio, por parte de los ciudadanos de la Unión, de la libertad de establecimiento garantizada por el Tratado» (apartado 63). Y a continuación, el Tribunal de Justicia se refiere a las excepciones o justificaciones pero también subraya que «las razones que pueden ser invocadas por un Estado miembro para justificar una excepción al principio de la libertad de establecimiento deben ir acompañadas de un análisis de la oportunidad y de la proporcionalidad de la medida restrictiva adoptada por dicho Estado miembro, así como de los datos precisos que permitan corroborar su argumentación» (apartado 83). Sin embargo, en este supuesto España no expuso ante el Tribunal de Justicia «datos suficientes para explicar por qué motivos las restricciones controvertidas son necesarias para alcanzar los objetivos perseguidos» (apartado 84). Sobre este particular, el Tribunal de Justicia considera contrarios al derecho de establecimiento: la prohibición de la Ley catalana de implantar grandes establecimientos comerciales fuera de la trama urbana consolidada de un número limitado de municipios; la limitación de la implantación de nuevos hipermercados a un reducido número de comarcas y la exigencia de que esos nuevos hipermercados no absorban más del $9 \%$ del consumo de productos de uso cotidiano o del $7 \%$ del consumo de productos de uso no cotidiano; o, en fin, la aplicación de límites en cuanto al grado de implantación y a la repercusión sobre el comercio minorista existente, más allá de los cuales no se podían abrir nuevos establecimientos comerciales grandes ni medianos.

En segundo lugar, el Tribunal de Justicia examina si la exigencia y los requisitos de obtención de una licencia comercial específica para la apertura de grandes establecimientos comerciales son conformes al Derecho de la Unión. A tal efecto, el Tribunal solo estima contrario a la libertad de establecimiento que la Comisión de Equipamientos Comerciales, que emite un informe sobre la procedencia de la licencia, esté integrada por representantes del comercio en la medida en que «el único interés sectorial representado en dicha Comisión es el del comercio local ya existente. Ahora bien, un organismo con esa composición, en el que no están representados los intereses relativos a la protección del medio ambiente y de los consumidores, mientras que sí lo están los competidores potenciales del solicitante de la licencia, no puede constituir un instrumento idóneo para alcanzar los objetivos de ordenación del territorio, de protección del medio ambiente y de protección de los consumidores» (apartado 111). 
En fin, la sentencia aborda determinados aspectos del procedimiento de concesión de la licencia comercial y el Tribunal de Justicia llega a la conclusión de que el régimen del silencio negativo y la cuantía de las tasas por otorgar las licencias no son contrarios al Derecho de la Unión Europea.

La sentencia de 24 de noviembre de 2011 declara que España ha incumplido la Directiva 89/552/CEE sobre radiodifusión televisiva (Directiva televisión sin fronteras) al permitir que determinados tipos de publicidad, como los publirreportajes, los anuncios de telepromoción, los anuncios publicitarios de patrocinio y los microespacios publicitarios fuesen emitidos en 2005 por las cadenas de televisión españolas durante un tiempo que excede el límite máximo del $20 \%$ del tiempo de emisión por hora.

A tal efecto, el Tribunal de Justicia reitera que «la protección de los consumidores que son los telespectadores frente a la publicidad excesiva constituye un aspecto esencial del objetivo de dicha Directiva» (apartado 45). Seguidamente, considera que el concepto de anuncio publicitario «debe interpretarse teniendo en cuenta el objetivo de ésta, consistente en conciliar el ejercicio de la libertad de difundir publicidad en televisión con la necesidad de proteger a los telespectadores frente a una difusión excesiva de publicidad» (apartado 49).

Por último, la sentencia de 26 de mayo de 2011 desestima el recurso por incumplimiento formulado por la Comisión contra España que aducía que la legislación urbanística valenciana no cumplía las exigencias establecidas en las Directivas sobre contratación pública. En particular, la Comisión le reprochaba a España que el procedimiento de adjudicación y aprobación de los programas de actuación integrada en gestión indirecta se sustraía a las normas de contratación pública a pesar de tratarse de verdaderos contratos de obras.

Sin embargo, el Tribunal de Justicia considera que la Comisión no ha demostrado que el objeto principal del contrato celebrado entre el ayuntamiento y el urbanizador corresponda a contratos públicos de obras en el sentido de las Directivas sobre contratos públicos, lo que constituye una condición previa para la declaración del incumplimiento alegado (apartado 98).

En esto parece que el Tribunal sigue las Conclusiones de su abogado general Niilo Jääskinen que advertía: «la inclusión de los PAI [programas de actuación integrada] en la categoría de contratos públicos de obras tendría la consecuencia práctica de desincentivar la iniciativa privada en el ámbito de la ordenación y el desarrollo territoriales, dado que, si se consideran incluidos en el ámbito de aplicación de las Directivas sobre contratos públicos, los PAI parecen contravenir el objetivo principal de la contratación pública, que es el de dispensar un trato igual a todos los participantes. La única opción que quedaría entonces en Derecho urbanístico sería el modelo 
clásico en el que los poderes públicos diseñan y aprueban todos los documentos relativos al planeamiento y el uso del suelo, y financian y organizan su ejecución y puesta en práctica, directamente y recurriendo a fondos públicos» (apartado 76 de las Conclusiones).

\section{Relación de las sentencias comentadas del tribunal de justicia}

1. TJ (Sala 3. ${ }^{\mathrm{a}}$ ), sentencia de 20 de enero de 2011, CLECE (C-463/09) (mantenimiento de los derechos de los trabajadores en caso de la transmisión de una empresa al Ayuntamiento de Cobisa).

2. TJ (Gran Sala), sentencia de 8 de marzo de 2011, Ruiz Zambrano (C-34/09) (ciudadanía de la Unión y nacionales de terceros países).

3. TJ (Sala 3. ${ }^{\mathrm{a}}$ ), sentencia de 10 de marzo de 2011, Telefónica Móviles España (C-85/10) (tasa por reserva del dominio público radioeléctrico para la prestación de servicios de telecomunicaciones).

4. TJ (Sala 6. ${ }^{\mathrm{a}}$ ), auto, de 18 de marzo de 2011, Montoya Medina (C-273/10).

5. TJ (Sala 2. ${ }^{a}$ ), sentencia de 24 de marzo de 2011, Comisión / España (C-400/08) (licencias de apertura de grandes superficies en Cataluña).

6. TJ (Gran Sala), sentencia de 3 de mayo de 2011, Tele2 Polska (C-375/09) (aplicación por la Comisión y por las autoridades nacionales de la competencia del artículo 102 TFUE).

7. TJ (Gran Sala), sentencia de 10 de mayo de 2011, Römer (C-147/08) (discriminación por orientación sexual en el cálculo de una pensión de jubilación).

8. TJ (Sala 7. ), sentencia de 19 de mayo de 2011, Barcenilla Fernández y Macedo Lozano (C-256/10 y C-261/10) (protección de los trabajadores frente al ruido y retribuciones).

9. TJ (Gran Sala), sentencias de 24 de mayo de 2011, Comisión / Bélgica (C-47/08), Comisión / Francia (C-50/08); Comisión / Luxemburgo (C-51/08); Comisión / Portugal (notarios) (C-52/08); Comisión / Austria (C-53/08); Comisión / Alemania (C-54/08); y Comisión / Grecia (C-61/08) (requisito de nacionalidad para el ejercicio de notario).

10. TJ (Sala 3. ${ }^{\mathrm{a}}$ ), sentencia de 26 de mayo de 2011, Comisión / España (C-306/08) (legislación urbanística valenciana y Directivas sobre contratos públicos).

11. TJ (Sala 8. ${ }^{\mathrm{a}}$ ), sentencia de 9 de junio de 2011, Campsa Estaciones de Servicio (C-285/10) (IVA de las operaciones entre empresas vinculadas).

12. TJ (Gran Sala), sentencia, de 14 de junio de 2011, Pfleiderer AG (C-360/09) (programas de clemencia y demandas civiles para reclamar daños antitrust). 
13. TJ (Gran Sala), sentencia de 12 de julio de 2011, L'Oréal y otros (C-324/09) (derecho de marca en Internet y límites de la protección judicial).

14. TJ (Sala 7.a), sentencia de 21 de julio de 2011, Telefónica de España (C-284/10) (tasa por la titularidad de autorizaciones generales y licencias individuales para la prestación de servicios de telecomunicaciones).

15. TJ (Sala 2. ${ }^{\mathrm{a}}$ ), sentencia de 8 de septiembre de 2011, Rosado Santana / Junta de Andalucía (C-177/10) (reconocimiento de antigüedad de funcionarios interinos).

16. TJ (Gran Sala), sentencia de 13 de septiembre de 2011, Prigge y otros (C-447/09) (jubilación forzosa de pilotos de avión).

17. TJ (Sala 4. ${ }^{\mathrm{a}}$ ), sentencia de 15 de septiembre de 2011, Gueye y Salmerón (C-483/09 y C-1/10) (estatuto de la víctima y delitos de violencia en el ámbito familiar).

18. TJ (Sala 1. a), sentencia de 15 de septiembre de 2011, Unió de Pagesos de Catalunya (C-197/10) (régimen de ayudas agrícolas).

19. TJ (Gran Sala), sentencia de 4 de octubre de 2011, Football Association Premier League y otros (C-403/08) (libre prestación de servicios y difusión televisiva de espectáculos deportivos).

20. TJ (Sala 3. ${ }^{\mathrm{a}}$ ), sentencia de 13 de octubre de 2011, Sousa Rodríguez y otros (C-83/10) (indemnización de pasajeros de transporte aéreo).

21. TJ (Gran Sala), sentencia de 15 de noviembre de 2011, Dereci y otros (C-256/11) (ciudadanía de la Unión y nacionales de terceros países).

22. TJ (Sala 3. ${ }^{\mathrm{a}}$ ), sentencia de 24 de noviembre de 2011, Scarlet Extended (C-70/10) (control de las descargas ilegales en Internet).

23. TJ (Sala 3. ${ }^{\mathrm{a}}$ ), sentencia de 24 de noviembre de 2011, Asociación Nacional de Establecimientos Financieros de Crédito Federación de Comercio Electrónico y Marketing Directo (C-468/10 y C-469/10) (derecho a la protección de datos personales).

24. TJ (Sala 1. ${ }^{a}$ ), sentencia de 24 de noviembre de 2011, Comisión / España (C-281/09) (anuncios publicitarios en televisión).

25. TJ (Sala 1. ${ }^{\mathrm{a}}$ ), sentencia de 8 de diciembre de 2011, Banco Bilbao Vizcaya Argentaria (C 157/10) (impuesto de sociedades y doble imposición). 